\title{
A cross-sectional survey of general practitioner knowledge, attitudes, and clinical experience of HIV PrEP
}

\author{
Sarah North ${ }^{1} \cdot$ Tony Joakim Sandset ${ }^{2} \cdot$ Anne Olaug Olsen ${ }^{1}$ (D) \\ Received: 25 January 2021 / Accepted: 18 June 2021 / Published online: 24 July 2021 \\ (C) The Author(s) 2021
}

\begin{abstract}
Aim Norway's health scheme provides no-cost HIV pre-exposure prophylaxis (PrEP) when prescribed by a specialist, typically preceded by a general practitioner's (GP) referral. The GP perspective with regard to PrEP implementation in Norway has yet to be captured.

Subject and methods We explored PrEP knowledge, attitudes, and clinical experience of GPs in the Norwegian capital of Oslo, where HIV incidence and PrEP demand are highest. An anonymous survey was designed and distributed between November 2019 and February 2020. Univariate and multivariate logistic regression analyses were performed to identify determinants of GPs' previous clinical PrEP experience (PrEP adoption).

Results One hundred and seventeen GPs responded to the survey. GP PrEP adopters were more likely to: identify as men (aOR 2.1; 95\% CI: 1.0-4.5); identify as lesbian, gay, or bisexual (LGB) (aOR 4.4; 95\% CI: 1.4-14.5); have $\geq 10$ LGB identifying patients on their list (aOR 4.4; 95\% CI:1.8-10.4); and self-report higher levels of PrEP knowledge (aOR 2.4; 95\% CI: 1.3-4.4). Conclusion Our findings suggest that GP PrEP knowledge is crucial to patient PrEP access. Educational interventions ought to be considered to enhance GP PrEP adoption capacities, such as easy-to-access PrEP guidelines and peer-based training opportunities in both online and in-person formats.
\end{abstract}

Keywords HIV prevention $\cdot$ Pre-exposure prophylaxis · General practitioner $\cdot$ Knowledge $\cdot$ Survey

\section{Introduction}

In response to successful oral HIV pre-exposure prophylaxis (PrEP) clinical trial findings (Baeten et al. 2012; Grant et al. 2010; McCormack et al. 2016; Molina et al. 2015), global health authorities have endorsed the implementation of PrEP service delivery to key populations as part of a combination HIV prevention strategy (Coleman 2018; WHO 2016; WHO 2019). In many EU/EEA countries with established implementation of PrEP programming, an apparent lack of patient uptake has been observed (Coleman 2018; McCormack et al. 2016). The European Centre for Disease Prevention and Control (ECDC) estimates that 500,000 men who have sex with

Anne Olaug Olsen

a.o.olsen@medisin.uio.no

1 Institute of Health and Society, Faculty of Medicine, University of Oslo, Postboks 1130, Blindern, 0318 Oslo, Norway

2 Centre for Sustainable Healthcare Education, Faculty of Medicine, University of Oslo, Oslo, Norway other men (MSM) in Europe would be likely to use PrEP, but lack access, a discrepancy dubbed the PrEP Gap (Hayes et al. 2019). Socio-political barriers potentially contributing to the PrEP Gap include the cost of both PrEP as a drug and the related service delivery (ECDC 2019), as well as the impact of anti-lesbian, -gay, -bisexual, and -transgender (LGBT) legislation within the EU/EEA on the quality of sexual healthcare service provision (European Union Agency for Fundamental Rights [FRA] 2014; Stromdahl et al. 2015). In countries with established PrEP implementation, healthcare providers with PrEP referring and/or prescribing privileges are considered to be the gatekeepers to patient PrEP access (Krakower and Mayer 2016), with the ability to facilitate or hinder PrEP service delivery. It is noteworthy that PrEP prescribing and/or referral privileges vary across regions; therefore, the term healthcare provider $(H C P)$ in this paper can be considered as an umbrella term for the variety of medical professions with PrEPprescribing and/or referral privileges.

A growing body of research is now examining the role of HCPs in implementing PrEP into practice (Krakower and Mayer 2016; Silapaswan et al. 2017; Turner et al. 2018; 
Zablotska and O'Connor 2017). It appears that the prescribing of PrEP is limited to a subgroup of "innovators and early adopters" (Krakower and Mayer 2016), where HCP knowledge level of PrEP is strongly associated with past and future PrEP-prescribing practices (Krakower and Mayer 2016; Silapaswan et al. 2017; Turner et al. 2018; Zablotska and O'Connor 2017). Additionally, compared to sexual health and HIV specialists, primary care providers often demonstrate lower PrEP knowledge and a lower willingness to prescribe PrEP (Zablotska and O'Connor 2017). HCP hesitancy to prescribe PrEP has been linked to logistical barriers, such as: clinical and laboratory monitoring, time constraints, and drug cost at the patient, health system, and state levels (Krakower and Mayer 2016; Silapaswan et al. 2017; Turner et al. 2018; Zablotska and O'Connor 2017). Furthermore, it has been noted that while some HCPs with PrEP-prescribing privileges might indicate a high level of PrEP acceptability, this has not always been reflected in their prescribing practices (Krakower and Mayer 2016). The disconnect between such acceptability and actual prescribing patterns is a suspected consequence of concerned HCP attitudes around PrEP efficacy, drug toxicity, and patient adherence (Krakower and Mayer 2016; Turner et al. 2018).

There is reason to wonder if HCP discomfort with PrEP prescribing could be an extension of an overall discomfort with sexual health service provision. One of the few studies that has broached the subject in the U.S. found some telling differences between HCP groups and their comfort performing clinical activities required for PrEP implementation (Petroll et al. 2017). The authors found that compared to HIV specialists, primary care providers reported a lower frequency of PrEP-related activities; such as initiating PrEP conversations with patients, and expressed particular discomfort with: discussing patient sexual activities, providing risk reduction counselling, and communicating an acute HIV diagnosis (Petroll et al. 2017). Furthermore, it has been argued that HCP discomfort with LGBT sexual health service provision, particularly in relation to PrEP prescribing, may be rooted in stigmatizing attitudes towards sex and sexuality (Calabrese et al. 2019; Skolnik et al. 2019; St.Vil et al. 2019). Instances of such stigma within healthcare settings have the potential to block patient access to PrEP, even when a patient may be eligible and initiating the conversation. As a result, patients who are unaware of existing and emerging sexually transmitted infection (STI) prevention strategies available to them may be left behind should they be reliant on HCPs to initiate such conversations (Adams et al. 2018; Skolnik et al. 2019).

At the time of this study, the majority of research on the role of HCPs in PrEP implementation had been carried out in North America (Krakower and Mayer 2016; Silapaswan et al. 2017; Turner et al. 2018; Zablotska and O'Connor 2017) and parts of Europe (Bil et al. 2018; Desai et al. 2016; Di Biagio et al. 2017; Gonçalves et al. 2018; Lions et al. 2019; Puro et al.
2013; Reyniers et al. 2018); however, Norway has yet to be represented in this domain. Norway is the second country in the world to provide no-cost oral PrEP to key populations through the national health scheme (ECDC 2019; Helsedirektoratet 2016). Individuals seeking PrEP must on their own, or by their general practitioner (GP), be referred to an STI clinic for a PrEP consultation and prescription (Hanlon et al. 2019; Helsedirektoratet 2016). In early 2019, approximately 1150 individuals in Norway had accessed PrEP, and the wait time for PrEP initiation within specialist care could take up to 52 weeks (Hanlon et al. 2019). While an ongoing national evaluation of PrEP implementation is monitoring the PrEP-user experience in Norway (Hanlon et al. 2019), the PrEP gatekeeper perspective has yet to be captured. The role of GPs must be examined to gain a balanced picture of PrEP implementation in Norway.

The overall aim of this study was to explore the selfreported PrEP knowledge, attitudes, and clinical experience of Norwegian GPs. Further, as sexual healthcare service provision is a prerequisite to identify eligible PrEP candidates (Nunn et al. 2017; Petroll et al. 2017), GP comfort and frequency with PrEP-related activities (Petroll et al. 2017) were also assessed. It was hypothesized that GPs who have already adopted PrEP into their clinical practice would have higher frequency of, and comfort with, PrEP-related activities.

\section{Methods}

The present study involved the design and distribution of a cross-sectional, self-administered, mixed-mode (web and mail), anonymous survey. With the exception of one survey tool targeting general public and patient samples (Jaspal et al. 2019), a formally validated instrument to measure GP attitudes towards PrEP could not be found. Survey items for the present study were adapted from previous studies (Bacon et al. 2017; Blackstock et al. 2017; Desai et al. 2016; Petroll et al. 2017; Puro et al. 2013; Reyniers et al. 2018), and modified to suit the Norwegian PrEP context. This resulted in a 56-item survey that could be completed in between 5 and $10 \mathrm{~min}$. To avoid alienating GPs lacking PrEP experience, respondents were invited to participate in a survey on sexual healthcare within general practice. Friendly language was used in the invitations and surveys to encourage GP participation, regardless of their experience or knowledge with the survey content.

\section{Study population and sample size}

Norway's capital of Oslo is the nation's most populated city (Høydahl 2020), where HIV incidence remains highest (Blystad et al. 2019), and is host location for the evaluation of PrEP implementation project (Hanlon et al. 2019). Consequently, Oslo could be considered the PrEP epicenter 
of Norway, and was the rationale for restricting our study population inclusion criteria to currently practicing GPs in Oslo. At the end of 2018, there were an estimated 527 practicing GPs in Oslo (Gaardsrud 2019). To calculate our target sample size in STATA (StataCorp 2017), we referred to a previous study of PrEP implementation among Belgian physicians (Reyniers et al. 2018) to base our assumptions of proportion/prevalence of GP PrEP adoption, and its association with PrEP knowledge and attitudes. A sample size of 112 Oslo GPs was required to achieve $80 \%$ power (at $5 \%$ significance level), while a sample of 148 Oslo GPs would achieve $90 \%$ power. A total of 117/527 Oslo GPs responded to our survey, resulting in a $22 \%$ response rate.

\section{Data collection}

Study invitations and surveys were distributed using a sequential web-mail recruitment method. The web survey invitation and subsequent reminders were first emailed to the head physician of each subdivision within Oslo, who then forwarded the survey to their respective GP listservs. The first web survey invite took place in November 2019, followed by two email reminders with a web survey link at 3-week intervals. Postal survey distribution took place in late January 2020 and contained, per GP within each clinic: one survey invitation letter, one survey, and one pre-stamped return envelope. Web and mail data collection closed in February 2020. Between the two survey modes, 44 respondents submitted responses to the web survey, while 73 respondents completed and returned the postal survey.

\section{Covariates}

Personal GP characteristics included demographic variables (gender identity, sexual orientation, country of birth), as well as details regarding clinical experience (location of medical exam, years of experience, number of GP colleagues in current practice setting). Respondents were provided the option of 'prefer to not answer' to survey items that could be perceived as too sensitive. Patient demographics were also captured by asking respondents to estimate the approximate number of LGBT patients $(0,<5,5-10,10+$, do not know), and proportion of patients belonging to an ethnic minority background $(<25 \%, 25-50 \%, 50 \%+$, do not know) currently on their list.

\section{Exposure variables}

One caveat to a GP referring eligible patients to a PrEP clinic is having completed a recent sexual history and STI screening. Survey items regarding GP self-reported comfort providing PrEP-related activities to patients of various demographics were measured using a five-point Likert scale; with the most negative response options (very uncomfortable, very difficult) coded as ' 1 ', ascending to the most positive response options (very comfortable, very easy) coded as ' 5 '. Five-point Likert scales were also used to measure the nine GP self-reported PrEP attitudes (strongly disagree to strongly agree). Selected Likert-scale survey items were combined to create unique composite scales that would act as continuous exposure measures in the data analysis. This resulted in four composite scales: GP comfort in discussing sex with LGBT identifying patients (four items, Cronbach's $\alpha=0.81$ ); GP comfort in discussing sex with patients from ethnic minority backgrounds (three items, Cronbach's $\alpha=0.77$ ); GP accepting attitudes towards PrEP (five items, Cronbach's $\alpha=0.74$ ); and GP concerned attitudes towards PrEP (four items, Cronbach's $\alpha=0.67)$. Accepting PrEP attitudes included statements such as: 'PrEP should remain free of cost' and 'It is reasonable to schedule control consultations every 3 months to healthy patients'. Concerned PrEP attitudes included 'PrEP could lead to an increase in patient HIV risk behaviours' and 'PrEP isn't necessary - condoms are already an effective HIV prevention strategy'.

In addition to the four composite exposure scales, two independent exposure variables were included in the multivariate analysis. GP self-reported PrEP knowledge was measured by one survey item with a six-point Likert scale (never heard of PrEP to excellent PrEP knowledge level) and treated as a continuous variable. As a proxy exposure to measure a GP's frequency of carrying out PrEP-related activities, we used the one categorical survey item capturing the number of syphilis tests provided by a GP in the last $3-\operatorname{month}$ period $(0,<5,5-$ $10,10+)$.

\section{Outcome variable}

The outcome variable of interest was GP PrEP adoption (Krakower and Mayer 2016; Turner et al. 2018). Survey respondents were asked if they had ever provided a patient with a referral or prescription for HIV PrEP. Respondents who answered 'yes' were classified as PrEP-adopters, while those who answered 'no' were classified as PrEP non-adopters.

\section{Data analysis}

Data analysis was completed with IBM SPSS version 25.0 (IBM Corp 2017). PrEP adoption was treated as a binary (adopter/non-adopter) outcome variable. Pairwise deletion was applied to covariates and exposure variables with low frequencies and/or missing data. The PrEP-related activity frequency proxy measure was treated as a categorical exposure variable. Mean scores were calculated for each respondent for each of the four composite exposure scales. Univariate and multivariate binary logistic regression analyses 
were used to investigate associations between the six exposure variables and the outcome of PrEP adoption. This was presented as unadjusted odds ratios (OR) with the accompanying 95\% confidence intervals (CIs).

To get the total effect of the exposure variables on the outcome of PrEP adoption, adjusted ORs (aORs) were calculated by controlling for the GP and patient demographics found to be significantly associated $(p<0.05)$ with PrEP adoption in the univariate analysis. Although not found to be significantly associated with PrEP adoption in the univariate analysis, we decided to include years of experience in general practice, location of medical exam, and the proportion (\%) of patients from ethnic minority backgrounds in the final logistic regression model. Years of experience in general practice was included as we assumed GPs with fewer years of experience might have more familiarity with PrEP, given that it is a relatively recent prevention innovation. The location of medical exam was of interest based on what might be implied with regard to sexual health medical training within and outside of Norway. The rationale to include the proportion of ethnic minority patients on a GPs list was based on the Norwegian Institute of Public Health's (NIPH) recommendation to increase comprehensive sexual healthcare access to MSM of ethnic minority backgrounds (Blystad et al. 2019).

\section{Results}

\section{GP and patient demographics}

Descriptive analyses of the survey GP respondents (Table 1) demonstrates that $80 \%(93 / 117)$ identified as heterosexual, $85 \%$ (99/117) were born in Norway, and 71\% (83/117) completed their medical training exam in Norway. About half $(49.6 \%)$ of respondents either claimed to not know or not have any transgender-identifying patients on their list. Twelve $(10.3 \%)$ of the respondents indicated either not knowing or having any LGB-identifying patients on their list. Most respondents answered having $\leq 25 \%$ patients from ethnic minority backgrounds on their list. Just over half (60/117) of respondents were classified as PrEP adopters, and the remaining 49\% (57/117) were classified as PrEP non-adopters.

Univariate analysis of GP and patient demographics in association with GP PrEP adoption demonstrated significant findings when it came to GPs who identified as men (OR 2.1; 95\% CI: $1.0-4.5$ ) and as LGB (OR 4.4; 95\% CI: 1.4 14.5). GPs who had ten or more LGB patients on their list were more likely to be PrEP adopters (OR 4.4; 95\% CI:1.810.4) (Table 1). Multivariate analysis of the main exposure composite scales (frequency of PrEP-related activities, comfort discussing sex with LGBT and ethnic minority background patients, self-reported PrEP knowledge, accepting and concerned attitudes towards PrEP) are presented in Table 2.

\section{Frequency and comfort with PrEP-related activities}

The number of syphilis tests provided by a GP in the last 3 months showed no association to GP PrEP adoption. Moreover, despite a majority of respondents indicating high comfort and ease discussing sex with patients, no significant association with PrEP adoption was observed (data not shown).

\section{PrEP knowledge and training needs}

Proportion frequencies for GPs' self-reported knowledge level of PrEP by adoption status (PrEP adopters vs PrEP nonadopters) are illustrated in Fig. 1. A GP's PrEP adoption status was significantly $(p<0.01)$ associated with level of selfreported PrEP knowledge (OR 2.4; 95\% CI: 1.3-4.4). For every one-unit increase in PrEP knowledge level (six-point Likert scale), there was an increase of 0.88 (95\% CI: 0.29 1.47) in the likelihood of a GP being a PrEP adopter.

\section{PrEP attitudes}

Frequencies (\%) of GP responses to the nine survey attitude statements can be seen in Fig. 3. In the multivariate analysis, neither one of the PrEP attitude scales (accepting, concerned) were found to be associated with PrEP adoption (Table 2).

\section{Discussion}

\section{Main findings}

This is the first study to our knowledge of any Nordic country to explore GP knowledge, attitudes, and clinical experience of HIV PrEP. We found that GP PrEP adopters were more likely to identify as men, LGB, and have ten or more LGB patients on their list. Our main finding with regard to the positive and significant association between GP PrEP knowledge and PrEP adoption appears to be consistent with previous studies (Krakower and Mayer 2016; Turner et al. 2018; Zablotska and O'Connor 2017).

Norway has made commendable advances in HIV prevention and treatment efforts, having recently surpassed the UNAIDS' 90-90-90 treatment targets (Whittaker et al. 2020), and estimated to have a minimal PrEP gap (Hayes et al. 2019). Still, such accolades are threatened by the noted association of low HCP PrEP knowledge negatively influencing PrEP adoption in general (Nunn et al. 2017; Petroll et al. 2017; St. Vil et al. St.Vil et al. 2019), as well as the lengthy PrEP specialist wait times documented in Oslo (Hanlon et al. 
Table 1 Factors associated with a GP having clinical experience with $\operatorname{HIV~PrEP}^{\dagger}(n=117)$

\begin{tabular}{|c|c|c|c|}
\hline & PrEP non-adopters $(n=57)$ & PrEP adopters $(n=60)$ & Univariate analysis OR $(95 \% \mathrm{CI})$ \\
\hline \multicolumn{4}{|l|}{ GP demographics ${ }^{\text {a }}$} \\
\hline \multicolumn{4}{|l|}{ Gender } \\
\hline Woman & $32(58.2)$ & $23(41.8)$ & 1 \\
\hline Man & $23(39.7)$ & $35(60.3)$ & $2.12(0.99-4.49) *$ \\
\hline \multicolumn{4}{|l|}{ Sexual orientation } \\
\hline Straight & $52(55.9)$ & $41(44.1)$ & 1 \\
\hline Lesbian, gay, bisexual & $4(22.2)$ & $14(77.8)$ & $4.44(1.36-14.51)^{*}$ \\
\hline \multicolumn{4}{|l|}{ Country of birth } \\
\hline Norway & $51(51.5)$ & $48(48.5)$ & 1 \\
\hline Elsewhere & $6(33.3)$ & $12(66.7)$ & $2.13(0.74-6.11)$ \\
\hline \multicolumn{4}{|l|}{ Location of medical exam } \\
\hline Elsewhere & $18(56.3)$ & $14(43.8)$ & 1 \\
\hline Norway & $38(45.8)$ & $45(54.2)$ & $1.52(0.67-3.46)$ \\
\hline \multicolumn{4}{|c|}{ Time working in general practice } \\
\hline$\leq 19$ years & $37(51.4)$ & $35(48.6)$ & 1 \\
\hline $20+$ years & $20(45.5)$ & $24(54.5)$ & $1.27(0.60-2.69)$ \\
\hline \multicolumn{4}{|l|}{ Number of GP colleagues } \\
\hline$<5$ & $38(49.4)$ & $39(50.6)$ & 1 \\
\hline $5+$ & $19(47.5)$ & $21(52.5)$ & $1.08(0.50-2.31)$ \\
\hline \multicolumn{4}{|l|}{ Patient demographics ${ }^{\mathrm{a}}$} \\
\hline \multicolumn{4}{|c|}{ Proportion from ethnic minority backgrounds } \\
\hline$<25 \%$ & $34(46.6)$ & $39(53.4)$ & 1 \\
\hline $25-50 \%$ & $13(52.0)$ & $12(48.0)$ & $0.81(0.32-2.00)$ \\
\hline $50 \%+$ & $9(56.3)$ & $7(43.8)$ & $0.68(0.23-2.02)$ \\
\hline \multicolumn{4}{|c|}{ Number of lesbian, gay, bisexual $^{\mathrm{b}}$} \\
\hline$<10$ & $24(68.6)$ & $11(31.4)$ & 1 \\
\hline $10+$ & $24(33.3)$ & $48(66.7)$ & $4.36(1.84-10.37)^{* *}$ \\
\hline \multicolumn{4}{|c|}{ Any trans men or trans women } \\
\hline Do not know & $12(60.0)$ & $8(40.0)$ & 1 \\
\hline No & $24(63.2)$ & $14(36.8$ & $0.88(0.29-2.66)$ \\
\hline Yes & $21(35.6)$ & $38(64.4)$ & $2.71(0.96-7.69)$ \\
\hline
\end{tabular}

GP, general practitioner; HIV PrEP, HIV pre-exposure prophylaxis; OR, odds ratio; trans, transgender

Binary logistic regression to determine demographics associated with a GP having clinical experience with PrEP (PrEP-adopter)

${ }^{\dagger}$ GPs with previous HIV PrEP clinical experience are classified as PrEP-adopters

${ }^{\text {a }}$ Total denominators vary slightly due to low frequencies $(n)$ and missing data

${ }^{\mathrm{b}}$ Respondents who answered "do not know" $(n=9)$ were excluded from the analysis

$* p<0.05$

$* * p \leq 0.001$

2019). As PrEP gatekeepers, GPs are integral to patient access to PrEP. GPs lacking PrEP awareness and knowledge run the risk of missing eligible PrEP candidates, therefore increasing Norway's PrEP Gap. The current regulatory division of labour between medical professions regarding PrEP prescribing privileges and provision of the associated ongoing care may already be fueling this gap in Norway (Simonsen 2020). Globally, many health systems with such a division in PrEP care delivery have observed a phenomenon known as the purview paradox; which refers to the lack of consensus among medical professions surrounding which among them should be responsible for the prescribing of PrEP and/or for the ongoing monitoring of PrEP users (Krakower et al. 2014). Infectious disease specialists have the expertise to identify eligible PrEP candidates and carry-out the required ongoing care; however, they are also more likely to already follow patients living with HIV. In contrast, GPs are more likely to see HIV-negative patients and are therefore better situated to 
Table 2 GP self-reported HIV PrEP-related service provision, knowledge level and attitudes in association with being a GP HIV PrEP-adopter ${ }^{\dagger}(n=$ 117)

\begin{tabular}{|c|c|c|}
\hline & Crude OR $(95 \% \mathrm{CI})$ & Adjusted OR $(95 \% \mathrm{CI})$ \\
\hline \multicolumn{3}{|l|}{ GP frequency of PrEP-related activities in the last three months ${ }^{\text {a }}$} \\
\hline 0 & Ref. & Ref. \\
\hline$<5$ & $2.17(0.85-5.51)$ & $1.73(0.52-5.75)$ \\
\hline $5-10$ & $1.46(0.50-4.25)$ & $0.94(0.21-4.18)$ \\
\hline $10+$ & $2.64(0.76-9.15)$ & $0.41(0.07-2.40)$ \\
\hline GP comfort discussing sex with LGBT patients ${ }^{b}$ & $1.52(0.95-2.43)$ & $1.02(0.51-2.04)$ \\
\hline GP comfort discussing sex with patients from ethnic minority backgrounds ${ }^{b}$ & $1.27(0.75-2.13)$ & $1.19(0.59-2.39)$ \\
\hline GP PrEP knowledge level ${ }^{\mathrm{b}}$ & $2.70(1.72-4.24)^{* *}$ & $2.42(1.34-4.36)^{*}$ \\
\hline GP accepting PrEP attitudes ${ }^{c}$ & $2.13(1.19-3.79)^{*}$ & $1.02(0.46-2.25)$ \\
\hline GP concerned PrEP attitudes ${ }^{c}$ & $0.94(0.51-1.74)$ & $1.33(0.64-2.79)$ \\
\hline
\end{tabular}

GP, general practitioner; PrEP, HIV pre-exposure prophylaxis; Ref., reference value; OR, odds ratio; LGBT, lesbian/gay/bisexual /trans

${ }^{\dagger}$ GPs with previous HIV PrEP clinical experience are classified as PrEP-adopters

${ }^{a}$ Adjusted for: GP gender, sexual orientation, years of experience in general practice, location of medical exam; number of LGB patients on list; proportion of patients from ethnic minority backgrounds; GP comfort discussing sex with LGBT patients; GP HIV PrEP knowledge

${ }^{\mathrm{b}}$ Adjusted for: GP gender, sexual orientation, years of experience in general practice, location of medical exam; number of LGB patients on list; proportion of patients from ethnic minority backgrounds

${ }^{\mathrm{c}}$ Adjusted for: GP gender, sexual orientation, years of experience in general practice, location of medical exam; GP HIV PrEP knowledge

$* p \leq 0.01$

$* * \mathrm{p} \leq 0.001$

initiate the PrEP care cascade, but often hold concerned attitudes and low knowledge of PrEP (Zablotska and O'Connor 2017). Nevertheless, there appears to be a need to better equip PrEP gatekeepers with the required knowledge, skills, and confidence to effectively identify and engage eligible PrEP users. Otherwise, there is the risk that patients may turn to obtaining PrEP through unconventional means. For example, a trend of informal PrEP use outside of healthcare settings has been observed within European and Central Asian countries (ECDC 2019). Findings from the 2017 European-Men-WhoHave-Sex-With-Men Internet Survey (EMIS) (Weatherburn et al. 2019) indicated that informal PrEP users primarily accessed PrEP by purchasing online and/or borrowing from a friend (ECDC 2019). Most concerning, one-third of EMIS-

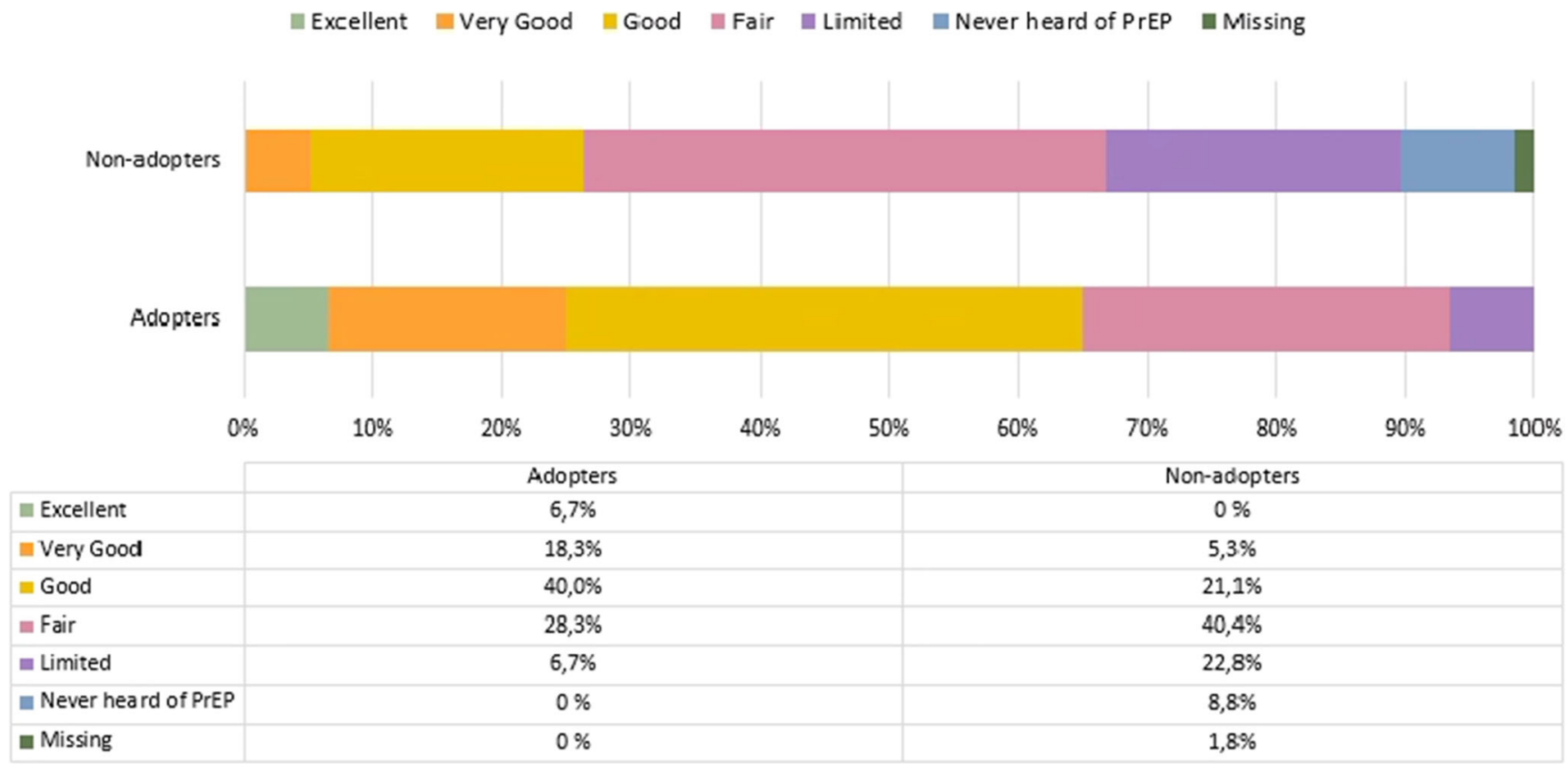

Fig. 1 Respondent self-reported HIV PrEP knowledge by HIV PrEP adoption status ( $n=117)$ 
2017 respondents accessing informal PrEP stated they had not disclosed their PrEP use to their healthcare provider(s) (ECDC 2019). Informally-accessed and/or unmonitored PrEP use can lead to negative outcomes for the individual, and as a result potentially burden healthcare systems by way of: the development and transmission of drug-resistant strains of HIV; compromised renal functioning; and complications due to undiagnosed/untreated STIs.

As PrEP formulations and guidelines continue to evolve, a collaborative and multi-sectoral effort is essential to adapt region-specific PrEP indications and training relayed to PrEP gatekeepers (Krakower and Mayer 2016; Sullivan and Siegler 2018; Zablotska and O'Connor 2017). Two unique models have been proposed to identify facilitators of accelerated PrEP implementation (Krakower and Mayer 2016; Zablotska and O'Connor 2017). Interestingly, both models advocate for peer-based education among HCPs. It is argued that peer education would be cost-effective and not only enhance knowledge of PrEP, but also build HCP skills in sexualhistory taking, assessing risk behaviours, and overall competence of sexual minorities (Zablotska and O'Connor 2017).

When GPs in our study survey were asked what they would need to have more informed conversations about PrEP with patients, we found that 74\% (42/57) of PrEP adopters and $89 \%(50 / 56)$ of PrEP non-adopters indicated they would need access to Norwegian PrEP guidelines (Fig. 2). We found it particularly intriguing that among PrEP adopters in our study, $53 \%(30 / 57)$ expressed a desire to build on PrEP adoption capacities in the form of an e-learning course, and 25\% (14/ 57) via the in-person opportunity to shadow a PrEPexperienced GP. This would suggest that PrEP adopters are aware of the necessity to maintain their self-reported highlevel PrEP knowledge, as it is crucial to stay informed of pertinent evidence-based findings and guideline revisions. On the other hand, this may also signal that PrEP nonadopters could benefit even more from such training and education, given the lack of PrEP implementation in their practice. Among PrEP non-adopters, 38\% (21/56) indicated a preference for an e-learning course on sexual history taking/sexual health in general, and 34\% (19/56) would need an e-learning course on PrEP.

\section{Limitations of the present study}

While our findings with regard to GP PrEP attitudes and PrEP adoption differed from the literature (Krakower and Mayer 2016; Turner et al. 2018; Zablotska and O'Connor 2017), they still merit some reflection. A commonly cited HCP PrEP concern has been risk compensation (Blumenthal and Haubrich 2014; Desai et al. 2017; Powell et al. 2019); essentially, the fear of increased HIV risk-taking behaviours among PrEP users, which will in turn burden healthcare systems via compromised drug efficacy, increased STI incidence, and antiretroviral therapy (ARV) resistance. We observed a large proportion of respondents indicating that they 'did not know' their level of agreement for many of the attitude statements (Fig. 3). A possible explanation for this finding may be attributed to the potential ambiguity of the attitude statements. For example, $48 \%$ (56/116) of respondents agreed or strongly agreed that "HIV PrEP could lead to an increase in STIs", which could be interpreted as a consequence of risk compensation. Alternatively, this same statement could be perceived as an acknowledgement that due to the amount of routine STI testing involved with PrEP care, more STIs are likely to be diagnosed earlier and treated. Consequently, our findings on any association between accepting and concerned GP attitudes on the PrEP adoption outcome were unclear.

According to one methodological review on HCP response rates to PrEP surveys, our $22 \%$ response rate $(117 / 527)$ can be considered fair (Silverman et al. 2018), albeit a limitation to the study. However, the challenge to obtain an acceptable HCP survey response rate has been well-documented (Cho et al. 2013; Kellerman and Herold 2001; Pit et al. 2014). At the same time, we are not able to rule out the presence of selection and non-response biases. There is a chance that only GPs interested and comfortable with topics related to sexual health participated in the survey, and/or did not answer truthfully to appear more comfortable and accepting of PrEP and related activities. Moreover, in the context of PrEP and HCP research, it has been argued that "not capturing a lack of adoption could result in an overestimation of the amount of providers offering PrEP and an underestimation of the need for PrEP-related medical training and dissemination efforts" (Silverman et al. 2018). However, it should be noted that the evaluation of non-response bias differs between physicians and the general public (Kellerman and Herold 2001). Physicians can be considered a homogenous group given their shared training, knowledge, attitudes, and behaviour; and therefore pose less of a concern of non-response bias compared to surveys of the general public (Kellerman and Herold 2001). Lastly, the interpretation of GP PrEP-related activity frequency was difficult to decipher based on the variation between ORs and AORs. This could suggest that the number of syphilis tests provided in the past 3 months was a poor proxy for frequency of PrEP-related activities.

\section{Recommendations}

Ensuring PrEP guidelines are streamlined and more readily accessible to GPs would be one approach to fostering GP knowledge and confidence to refer eligible patients for PrEP. Hence, consolidating existing sexual healthcare service provision guidelines to include the indications and care for PrEP, and making said guidelines easily accessible, is one suggested manner in which our research findings can be translated and implemented into general practice. Further, the 


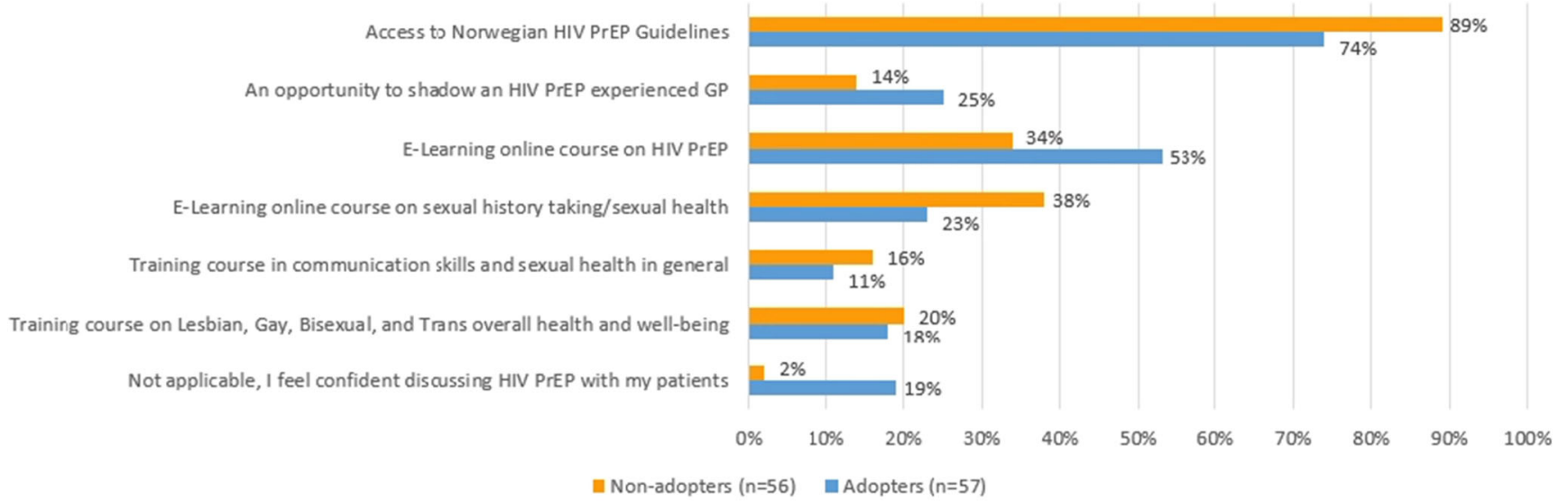

Fig. 2 Respondent identified training needs by HIV PrEP adoption status $(n=113)$

opportunity to shadow GPs familiar with PrEP in clinical settings provides one avenue of peer-education which might be suitable in certain settings wherein GPs have both time and resources for such educational training. While this recommendation has been highlighted in the current literature (Krakower and Mayer 2016; Zablotska and O'Connor 2017), it should be noted that such training presupposes building infrastructure and capacities so that GPs who may want training can both gain access and have the time to participate. Moreover, this would also entail that a network of PrEP adopters would be available to provide such training in a formalized manner. As such, this form of peer-based education might require extensive resources and therefore may not be suitable for all settings. Consequently, online peer-based training may be more feasible to coordinate, via webinars or digital pre-recorded educational materials. Lastly, given the literature linking high HCP PrEP knowledge with high knowledge of and comfort with PrEP-related activities, (Nunn et al. 2017; Petroll et al. 2017; St. Vil et al. St.Vil et al. 2019), further research may be warranted to investigate if our findings are echoing a gap within sexual healthcare service provision in general.

\section{Conclusion}

It is unclear if the attitudes of Oslo GPs towards PrEP play a role in their adoption of PrEP in clinical practice. However, it is evident that the level of GP PrEP knowledge is crucial to GP PrEP adoption, and therefore a key component to the effective roll-out of PrEP to eligible patients. Educational interventions ought to be considered to enhance GP confidence and capacities to adopt PrEP within clinical practice; for example, providing GPs with streamlined access to PrEP guidelines, as well as online and in-person opportunities to participate in peer-based trainings. Equipping GPs with the latest PrEP guidelines, which are easily accessible, is a simple and effective intervention that should not be overlooked.

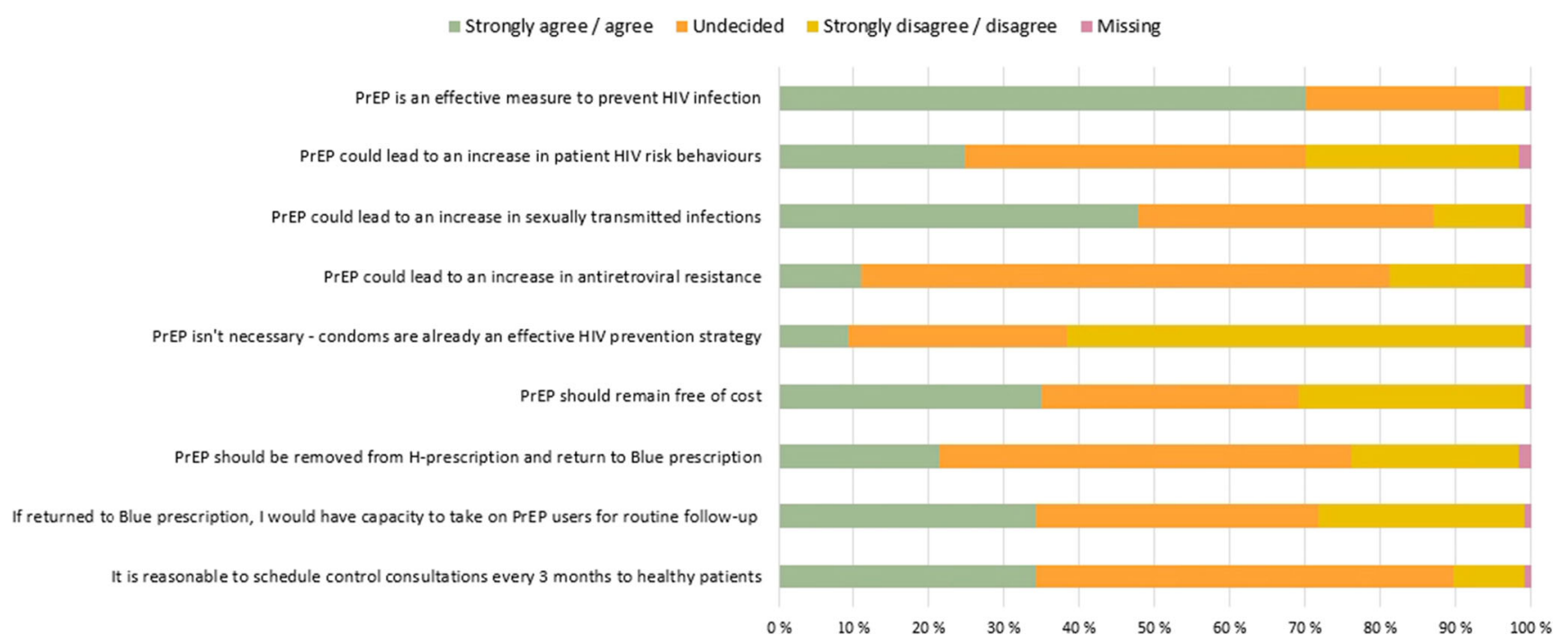

Fig. 3 Respondent self-reported attitudes towards $\operatorname{HIV} \operatorname{PrEP}(\mathrm{N}=117)$ 
Acknowledgements The authors are thankful to all study participants, and to Oslo district head physicians who facilitated recruitment. The authors would also like to acknowledge the financial support provided by an Osloforskning grant, through the Department of Sociology and Social Geography, University of Oslo, Norway.

Authors' contributions S.N. was responsible for the study design, data collection, and analysis, and prepared the manuscript. A.O.O. and T.J.S. critically reviewed the study design from start to finish in addition to the manuscript. A.O.O. and T.J.S. contributed greatly to the interpretation of findings. All authors approved the final version of the manuscript.

Funding Open access funding provided by University of Oslo (incl Oslo University Hospital). This study was partially funded by a grant from Osloforskning, Department of Sociology and Social Geography, University of Oslo, Norway.

Data availability Inquiries regarding raw data access permissions must be advised by the University of Oslo Data Protection Officer and Services for sensitive data (TSD in Norwegian), and in accordance with the General Data Protection Regulation (GDPR).

Code availability Software application and/or coding requests must be advised by the University of Oslo Data Protection Officer and Services for sensitive data (TSD in Norwegian), and in accordance with the General Data Protection Regulation (GDPR)

\section{Declarations}

Conflict of interest On behalf of all authors, the corresponding author states that there is no conflict of interest.

Ethics approval The present study protocol and survey materials were reviewed by the University of Oslo (UiO) and the Norwegian Centre for Research Data (NSD in Norwegian). As there was no collection of respondent personal medical information, ethical approval from the Regional Committees for Medical and Health Research Ethics (REK in Norwegian) was deemed unnecessary. The project was carried out in accordance with the All European Academies' (ALLEA) European Guidelines for Research Integrity, the 2017 Norwegian Research Ethics Act, and the 1979 Belmont Report.

Consent to participate Potential survey respondents were informed in the web and mail invitation letters of their right to freely participate, and that since the survey was anonymous, it would not be possible to retract submitted responses. Therefore, consent to participate was implied by respondents submitting their completed survey, by post or web. To enhance the survey response rate, potential respondents were informed that if a $50 \%$ response rate was achieved, a monetary donation would be made to a local charitable health/social service organization; to be nominated by the majority of respondents.

Consent for publication All authors consent to the publication of this manuscript.

Open Access This article is licensed under a Creative Commons Attribution 4.0 International License, which permits use, sharing, adaptation, distribution and reproduction in any medium or format, as long as you give appropriate credit to the original author(s) and the source, provide a link to the Creative Commons licence, and indicate if changes were made. The images or other third party material in this article are included in the article's Creative Commons licence, unless indicated otherwise in a credit line to the material. If material is not included in the article's
Creative Commons licence and your intended use is not permitted by statutory regulation or exceeds the permitted use, you will need to obtain permission directly from the copyright holder. To view a copy of this licence, visit http://creativecommons.org/licenses/by/4.0/.

\section{References}

Adams LM, Balderson BH, Brown K et al (2018) Who starts the conversation and who receives preexposure prophylaxis (PrEP)? A brief online survey of medical providers' PrEP practices. Health Educ Behav 45:723-729. https://doi.org/10.1177/1090198117752789

Bacon O, Gonzalez R, Andrew E et al (2017) Brief report: informing strategies to build PrEP capacity among San Francisco Bay Area clinicians. J Acquir Immune Defic Syndr 74:175-179. https://doi. org/10.1097/QAI.0000000000001182

Baeten JM, Donnell D, Ndase P et al (2012) Antiretroviral prophylaxis for HIV prevention in heterosexual men and women. N Engl J Med 367:399-410. https://doi.org/10.1056/NEJMoa1108524

Bil JP, Hoornenborg E, Prins M et al (2018) The acceptability of preexposure prophylaxis: beliefs of health-care professionals working in sexually transmitted infections clinics and HIV treatment centers. Front Public Health 6:5. https://doi.org/10.3389/fpubh.2018.00005

Blackstock OJ, Moore BA, Berkenblit GV et al (2017) A cross-sectional online survey of HIV pre-exposure prophylaxis adoption among primary care physicians. J Gen Intern Med 32:62-70. https://doi. org/10.1007/s11606-016-3903-z

Blumenthal J, Haubrich RH (2014) Will risk compensation accompany pre-exposure prophylaxis for HIV? Virtual Mentor 16:909-915. https://doi.org/10.1001/virtualmentor.2014.16.11.stas1-1411

Blystad H, Caugant D, Kløvstad H et al (2019) Årsrapport 2018: Overvåkning av seksuelt overførbare infeksjoner og blodbårne hepatitter [Annual Report 2018: surveillance of sexually transmitted infections and blood-borne hepatitis]. Folkehelseinstituttet [National Institute of Public Health], Oslo. https://www.fhi.no/globalassets/ dokumenterfiler/rapporter/2019/arsrappor-blod-og-sex-2018.pdf. Accessed 1 august 2019. Bokmål Norwegian

Calabrese SK, Tekeste M, Mayer KH et al (2019) Considering stigma in the provision of HIV pre-exposure prophylaxis: reflections from current prescribers. AIDS Patient Care STDS 33:79-88. https:// doi.org/10.1089/apc.2018.0166

Cho YI, Johnson TP, VanGeest JB (2013) Enhancing surveys of health care professionals: a meta-analysis of techniques to improve response. Eval Health Prof 36:382-407. https://doi.org/10.1177/ 0163278713496425

Coleman R (2018) Setting the scene, setting the targets. The joint United Nations Programme on HIV/AIDS prevention targets of 2016 and estimating global pre-exposure prophylaxis targets. Sex Health 15: 485-488. https://doi.org/10.1071/SH18147

Desai M, Field N, Grant R et al (2017) State of the art review: recent advances in pre-exposure prophylaxis for HIV. BMJ 359:j5011. https://doi.org/10.1136/bmj.j5011

Desai M, Gafos M, Dolling D et al (2016) Healthcare providers' knowledge of, attitudes to and practice of pre-exposure prophylaxis for HIV infection. HIV Med 17:133-142. https://doi.org/10.1111/hiv. 12285

Di Biagio A, Riccardi N, Signori A et al (2017) PrEP in Italy: the time may be ripe but who's paying the bill? A nationwide survey on physicians' attitudes towards using antiretrovirals to prevent HIV infection. PLoS One 12:e0181433. https://doi.org/10.1371/journal. pone. 0181433

European Centre for Disease Prevention and Control (ECDC) (2019) Continuum of HIV care: monitoring implementation of the Dublin 
Declaration on partnership to fight HIV/AIDS in Europe and Central Asia: 2018 progress report. ECDC, Stockholm. https://doi.org/10. $2900 / 89066$

European Union Agency for Fundamental Rights (FRA) (2014) EU LGBT survey - European Union lesbian, gay, bisexual and transgender survey - main results. FRA, Luxembourg. https://doi.org/ $10.2811 / 37969$

Gaardsrud PØ (2019) Styringsdata for fastlegeordningen, 4. Kvartal 2018 [management data for the GP scheme, 4th quarter 2018]. Helsedirektoratet [Norwegian Directorate of Health], Oslo. https:// www.helsedirektoratet.no/statistikk/fastlegestatistikk. Accessed 1 June 2019. Bokmål Norwegian

Gonçalves RB, Marreiros A, Augusto GF (2018) Portuguese health care providers' knowledge, attitudes, and acceptability of HIV preexposure prophylaxis. HIV AIDS Rev 17:249-258. https://doi.org/ 10.5114/hivar.2018.80256

Grant RM, Lama JR, Anderson PL et al (2010) Preexposure chemoprophylaxis for HIV prevention in men who have sex with men. N Engl J Med 363:2587-2599. https://doi.org/10.1056/NEJMoa1011205

Hanlon M, MacLeod J, Pettersen F et al (2019) Evalueringsrapport: Oppdatering av PrEP-implementeringen i Norge [Evaluation report: Update of the PrEP implementation in Norway]. Nasjonal kompetansetjeneste for seksuelt overførbare infeksjoner (NKSOI) og Olafiaklinikken, Oslo Universitetssykehus [National Competence Service for Sexually Transmitted Infections (NKSOI) and Olafiaklinikken, Oslo University Hospital], Oslo. https://oslouniversitetssykehus.no/seksjon/nasjonal-kompetansetjeneste-forseksuelt-overforte-infeksjoner/Documents/PrEP\% 20implementeringen\%20i\%20Norge.pdf. Accessed 1 May 2019. Bokmål Norwegian

Hayes R, Schmidt AJ, Pharris A et al (2019) Estimating the 'PrEP gap': how implementation and access to PrEP differ between countries in Europe and Central Asia in 2019. Euro Surveill 24(41):1900598. https://doi.org/10.2807/1560-7917.ES.2019.24.41.1900598

Helsedirektoratet [Norwegian Directorate of Health] (2016) Preeksponeringsprofylakse - PrEP - muligheter for vellykket implementering i Norge [Pre-exposure prophylaxis - PrEP- opportunities for successful implementation in Norway]. Helsedirektoratet, Oslo. https://www.legeforeningen.no/ contentassets/71059b88efc84665bc313e87e81 ceb5f/prep-notatmed-anbefalinger-010916.pdf. Accessed 1 March 2019. Bokmål Norwegian

Høydahl E (2020) Population and land area in urban settlements. Statistics Norway. https://www.ssb.no/en/beftett/.

IBM Corp (2017) IBM SPSS Statistics for Macintosh, Version 25.0. IBM Corp, Armonk, NY

Jaspal R, Lopes B, Maatouk I (2019) The attitudes toward pre-exposure prophylaxis (PrEP) scale: development and validation. J HIV AIDS Soc Serv 18:197-205. https://doi.org/10.1080/15381501.2019. 1596861

Kellerman SE, Herold J (2001) Physician response to surveys: a review of the literature. Am J Prev Med 20:61-67. https://doi.org/10.1016/ S0749-3797(00)00258-0

Krakower D, Mayer KH (2016) The role of healthcare providers in the roll out of preexposure prophylaxis. Curr Opin HIV AIDS 11:4148. https://doi.org/10.1097/coh.0000000000000206

Krakower D, Ware N, Mitty JA et al (2014) HIV providers' perceived barriers and facilitators to implementing pre-exposure prophylaxis in care settings: a qualitative study. AIDS Behav 18:1712-1721. https://doi.org/10.1007/s10461-014-0839-3

Lions C, Cabras O, Cotte L et al (2019) Missed opportunities of HIV preexposure prophylaxis in France: a retrospective analysis in the French DAT'AIDS cohort. BMC Infect Dis 19:278. https://doi.org/ 10.1186/s12879-019-3915-5

McCormack S, Dunn DT, Desai M et al (2016) Pre-exposure prophylaxis to prevent the acquisition of HIV-1 infection (PROUD): effectiveness results from the pilot phase of a pragmatic open-label randomised trial. Lancet 387:53-60. https://doi.org/10.1016/s01406736(15)00056-2

Molina JM, Capitant C, Spire B et al (2015) On-demand preexposure prophylaxis in men at high risk for HIV-1 infection. N Engl J Med 373:2237-2246. https://doi.org/10.1056/NEJMoa1506273

Nunn AS, Brinkley-Rubinstein L, Oldenburg CE et al (2017) Defining the HIV pre-exposure prophylaxis care continuum. AIDS 31:731734. https://doi.org/10.1097/QAD.0000000000001385

Petroll AE, Walsh JL, Owczarzak JL et al (2017) PrEP awareness, familiarity, comfort, and prescribing experience among US primary care providers and HIV specialists. AIDS Behav 21:1256-1267. https:// doi.org/10.1007/s10461-016-1625-1

Pit SW, Vo T, Pyakurel S (2014) The effectiveness of recruitment strategies on general practitioner's survey response rates - a systematic review BMC Med Res Methodol 14. https://doi.org/10.1186/14712288-14-76

Powell VE, Gibas KM, DuBow J et al (2019) Update on HIV Preexposure prophylaxis: effectiveness, drug resistance, and risk compensation. Curr Infect Dis Rep 21(8):28. https://doi.org/10. 1007/s11908-019-0685-6

Puro V, Palummieri A, De Carli G et al (2013) Attitude towards antiretroviral pre-exposure prophylaxis (PrEP) prescription among HIV specialists. BMC Infect Dis 13:217. https://doi.org/10.1186/14712334-13-217

Reyniers T, Vuylsteke B, Pirotte B et al (2018) Physicians' preparedness for pre-exposure prophylaxis: results of an online survey in Belgium. Sex Health 15:606-611. https://doi.org/10.1071/SH18072

Silapaswan A, Krakower D, Mayer KH (2017) Pre-exposure prophylaxis: a narrative review of provider behavior and interventions to increase PrEP implementation in primary care. J Gen Intern Med 32:192198. https://doi.org/10.1007/s11606-016-3899-4

Silverman TB, Schrimshaw EW, Franks J et al (2018) Response rates of medical providers to internet surveys regarding their adoption of Preexposure prophylaxis for HIV: methodological implications. J Int Assoc Provid AIDS Care 17:1-6. https://doi.org/10.1177/ 2325958218798373

Simonsen MCA (2020) Bekymret for at Norge havner bakpå — håper på endring [Concerned that Norway will fall behind - hoping for change]. Dagins Medisin [Daily Medicine], Oslo. https://www. dagensmedisin.no/artikler/2020/12/01/bekymret-for-at-norgehavner-bakpa\%2D\%2Dna-haper-vi-pa-endring/. Accessed 1 December 2020. Bokmål Norwegian

Skolnik AA, Bokhour BG, Gifford AL et al (2019) Roadblocks to PrEP: what medical records reveal about access to HIV pre-exposure prophylaxis. J Gen Intern Med 35:832-838. https://doi.org/10.1007/ s11606-019-05475-9

St.Vil NM, Przybyla S, Lavalley S (2019) Barriers and facilitators to initiating PrEP conversations: perspectives and experiences of health care providers. J HIV AIDS Soc Serv 18:166-179. https:// doi.org/10.1080/15381501.2019.1616027

StataCorp (2017) Stata statistical software: release 15. StataCorp LLC, College Station, TX

Stromdahl S, Hickson F, Pharris A et al (2015) A systematic review of evidence to inform HIV prevention interventions among men who have sex with men in Europe. Euro Surveill 20(15):21096. https:// doi.org/10.2807/1560-7917.es2015.20.15.21096

Sullivan PS, Siegler AJ (2018) Getting pre-exposure prophylaxis (PrEP) to the people: opportunities, challenges and emerging models of PrEP implementation. Sex Health 15:522-527. https://doi.org/10. 1071/sh18103

Turner L, Roepke A, Wardell E et al (2018) Do you PrEP? A review of primary care provider knowledge of PrEP and attitudes on prescribing PrEP. J Assoc Nurses AIDS Care 29:83-92. https://doi.org/10. 1016/j.jana.2017.11.002 
Weatherburn P, Hickson F, Reid DS et al (2019) EMIS-2017 - the European Men-Who-Have-Sex-With-Men Internet Survey. Key findings from 50 countries. ECDC, Stockholm. https://doi.org/10. 2900/690387

Whittaker R, Nilsen Ø, Myrberg AJ et al (2020) Norway is on the verge of ending the HIV epidemic. Tidsskr Nor Laegeforen 140(18). https://doi.org/10.4045/tidsskr.20.0748

World Health Organization (WHO) (2016) Consolidated guidelines on the use of antiretroviral drugs for treating and preventing HIV infection: recommendations for a public health approach, 2nd edn. WHO, Geneva. https://apps.who.int/iris/bitstream/handle/10665/208825/ 9789241549684_eng.pdf?sequence $=1$.
World Health Organization (WHO) (2019) What's the 2+1+1? Eventdriven oral pre-exposure prophylaxis to prevent HIV for men who have sex with men: update to WHO's recommendation on oral PrEP. WHO, Geneva. https://apps.who.int/iris/bitstream/handle/ 10665/325955/WHO-CDS-HIV-19.8-eng.pdf?ua=1.

Zablotska IB, O'Connor CC (2017) Preexposure prophylaxis of HIV infection: the role of clinical practices in ending the HIV epidemic. Current HIV/AIDS reports 14:201-210. https://doi.org/10.1007/ s11904-017-0367-7

Publisher's note Springer Nature remains neutral with regard to jurisdictional claims in published maps and institutional affiliations. 